\title{
Photography as Urban Narrative
}

\author{
Pushpa Arabindoo \\ Photographs by Christophe Delory
}

\begin{abstract}
Questioning whether we think as much about how we write as to what we write, I undertook recently a more rigorous reflection on what I saw as an exercise in 'writing the city into the urban'. As I encountered the risk of writing the city out of the urban, I sought to write the city (creatively) back into the (critical) urban. It involved a gesture where photographic images of the city offered new meanings to the textual abstraction of the urban. It is no small act, nor an innocent one. It is also a longstanding one in the representational practices of writing the city. The simple task of juxtaposing photographs with a text while offering new ingenious forms of 'writing', opens up questions of not only how these images could very well question the validity of the text but also how photography's ability to generate an archive of the (city's) present draws attention to its own ethnographic (im)possibilities and epistemological crisis.
\end{abstract}

Keywords: writing the city, urban, Chennai, photography, hinterland

Perumbakkam is one of many non-descript neighbourhoods in the fringes of Chennai - you could pass by any number of such localities in your daily encounters with the city without so much as a second glance. Surprisingly, there is a Wikipedia entry identifying it as a suburb of Chennai and usefully gives its coordinates: $12.9053 \mathrm{~N}$ and 80.1986 E. Despite this precision, it is hard to tell where it begins and where it ends, even though, Wikipedia again informs that it is bound by Shollinganallur to the east, Semmenchery to the south, Medavakkam to the north and Sithalapakkam to the west, all equally difficult to define with geo-locational exactitude. This is hardly helped by the fact that there is little to distinguish it despite some poignant historical moments and what were once remarkable natural features. For, at one point in history, the Great Trigonometric Survey in colonial India commenced in 1802 with the measurement of a baseline from Perumbauk Hill, 7.5 miles in length to the more popular landmark of St Thomas's Mount in the north. Today, we can see little of this hill and not much remains of its great lake which is a crucial part of a larger wetland eco-system (Pallikaranai Marshes) reduced to a fragmented entity fighting the pressures of urbanisation. And yet, it is to places such as Perumbakkam that I find myself returning again and again in my efforts to characterise the specificities of urbanisation in a city like Chennai. It began more than a decade ago when I visited Perumbakkam to typify the phenomenon 
of peri-urbanisation and to make sense of a transformation that is neither an urbanisation of the rural condition nor a ruralisation of the urban setting. In fact, if I am going to be provocative, I can even argue that it is in locations such as Perumbakkam that one needs to look for a paradigmatic refreshing of a globalised idea of the urban. This is more than peripheral urbanisation belying straightforward assumptions of peripheralization through its exposure to explicit globalising imperatives. Here, you find a condition of heterogeneity created by the presence of various social groupings including 'real-estate developers, global investors, liberalizing government officials, bourgeois urbanites, and peasants with de facto land rights', not to mention already existing as well as incoming rural migrants (Roy 2003, 144). Equally important is the fact that Perumbakkam strives to establish a relational reference not with the centrality of the city but to an infrastructure that bypasses the city - the IT Corridor, demonstrating a new logic of development trajectory that is outside of the centre. Perumbakkam signifies a production of the urban which is more than a literal mode of outward spatial expansion, displaying a process of urbanisation that muddies questions of what is urban and what is non-urban. Its rapid development in the past couple of decades has been mediated through a broad array of institutional, political, social and environmental factors (sometimes relying on their absence rather than their presence) and involves a simultaneous organisation at a range of spatial scales. We witness the emergence of an assortment of morphological forms and settlement typologies straddling across the natural to the urban ecosystem. There is also a hyperreality to its urbanisation involving a new economic geography of extraction, production and circulation, one that can no longer be seen through the idiom of twentieth-century agglomeration processes. Perumbakkam thus constitutes a new geography of hinterland where lands that were once subject to nature's seasonal behaviour or even agrarian regulatory modes are unrelentingly forced to make way for a broadened category of the urban, indicative of a new articulation of territories, landscapes and ecologies.

It is thus a challenge to subject places such as Perumbakkam to a rigorous empirical scrutiny, one that captures its 'affective landscapes and moods' (de Boeck and Simone 2015: 85) especially in the context of a rapidly shifting theoretical ground that requires 
you to borrow more than vocabulary from a range of disciplines cutting across the social and natural sciences, providing an accounting of not just the actions of humans but plants, animals, soils, climates and a vast category of nonhuman entities. To comprehend this complex phenomenon and its transformation is no easy task. Over the years, I have traversed this ever changing landscape innumerable times to capture the details of this emergent form of hinterland urbanism. It has involved employing a range of methodological tactics such as conversations and interviews to sound recordings of anything pertinent (bird/animal calls to vehicular and construction noises or the multitude of human voices in all manner of contextualities - chit-cat to traders selling goods), mapping and sketching its land conversions, not in any manner of cadastralisation but to emphasise the absence of one. Along the way, I have taken innumerable photographs with my iPhone which despite descriptions as a disruptive technology in amateur photography (Chesher 2012) has been gainfully used to index changes that are quite difficult to register in a systematic way. And yet, when I begin to make sense of this rich array of 'raw' material, I find myself frequently running them through a 'quick-wash' cycle of academic writing, a conversion that strips them of their panoply of meanings and forces them instead to follow a rigid grammar of a narrow theoretical consensus. I have tried to rectify this through a more narrative form of writing, one that is taken from the literary genre of storytelling to capture the discontinuities and contradictory experiences and to make sense of an overwhelmingly crowded and disordered chronological reality (Cronon 1992). Even though such narratives resist the temptation of simple chronicling or sequencing of events, the fact that it still favours the written format rankles. It was thus I found myself undertaking a serious engagement with the question of writing the city, one that I deliberately framed as the challenge of 'writing the city into the urban', as I realised that my preoccupation with writing into the urban meant a writing out the city or even worse, an exercise in writing against the city. In an effort to open up new ways of writing, I looked to create space beside (the) text and hence turned to the possibility of photographs whose images provide an analytical narrative to visually writing the city, paralleling the verbal writing of the urban. 
I thus returned to Perumbakkam in February 2019 with a photographer, Christophe Delory, to see if this collaboration would open up more ingenious forms of writing. It was an intense experience where, over a period of ten days, despite much planning, we had to follow the camera's discretion, a machine-organism favouring as much the distant gaze and panoramic views as intimate close-ups as we searched for decisive moments. There were times when the city would play a recalcitrant child and hide in shadows (more than poor lighting being a reason) posing a dilemma of techne as well as episteme. It was sometimes awkward as the familiar was rendered strange and the strange became familiar, and not in any particular order. Our intention was not to produce an "urban photogenie" (Chevrier 2006 cited in Burris 2011), as we tackled the challenge of bringing the city to focus. Instead, as the Belgian anthropologist Filip de Boeck along with his photographer-collaborator Marie-Françoise Plissart (2014 [2003]) found, the city constantly remains out of focus, its energy and movement refusing to be frozen neither in linear text nor in static images. His collaborations with photographers show that a straightforward linear narrative of the city is impossible and that photographs/videos subordinate chronology to the analytic/narrative demands of the sequence. Nevertheless, what emerges is a heterodox interaction between the visual and the verbal under the burden of the urban where neither the photographic image nor the plain text can claim to be the primary narrator, and in its own sub-space the city still refuses to be written so easily.

Photography as ethnography/epistemology: Archive of the present The anthology of images we were able to assemble through the sheer mass of photographs taken indicates another kind of ethnography, one that de Boeck (2016) uses to uncover Kinshasa's 'urban now', a moment he describes as being suspended between lingering precolonial references, the broken dreams of a colonial past, and the not yet realised promises of neoliberal futures. Following Robinson (2013), we could ask: what sort of an analytic of the present might we tap into for construing an urban 'now' that involves co-temporalities of pasts, presents and futures. It is in pursuing this line of question that we need to explore further the way photographs saturate the idea of city as not just an archive, but 'an archive of the present'. As Derrida (2010) reminds us, the archive of the photograph is constituted by the present 
itself where, even as the present is lost, the archive remains. Elaborating on the idea of city-as-archive, Rao (2009) goes beyond common sense understandings of archives to use the notion of archive as a way of navigating the voids of the present, as a practice of intervening into and reading the urban fabrics created by these voids. She argues for a new methodological move to posit the transforming city itself as an archive in the making, even as problems of method connect to matters of the present. Here, photography as ethnography allows to exploit the historicity of the present, mediating between the two, through experimental forms of writing where we read/write the text as image and vice versa to overcome photography's own epistemological crisis.

Coda:

In my eagerness and perhaps anxiety to (re)think my encounter with the city and Perumbakkam in particular through and via photography, I have to confess that I haven't reflected much on the kind of exchange that takes place between the writer and the photographer. While the division of labour between us was distinct on 'field', it risked the possibility of blurring and spilling over as we got to the subsequent task of organising text and image. There was one instance when we had arrived at a slum resettlement development in Perumbakkam. I had been there a few times 'doing fieldwork' but this time it was different, obviously, as I was accompanied by a 'white male photographer'. Women who had previously conveyed to me tales of despair insisting 'what you see here is housing not a home' were keen to invite the photographer into their domestic realm to show how they had, after all, made a home for themselves. I realised that the story I had constructed before of utter hopelessness was only a partial truth as my earlier cursory perceptions registered through the glance of a naked eye had been lost in a discursive language. As I am still mulling over this revelation, this essay has been written in a way to sustain this early division of labour where the domain of text and images are kept separate. I, therefore, hesitate to call this a photo-essay, not due to any major concerns around the invasion of text over image or vice versa but, as Mitchell (1994) remarked, photographic essays tend to occupy a strange conceptual space in our understanding of representation disbanding our ubiquitous belief in the visual as the realm of experience totally separated from and antithetical to the verbal. Rather, it is simply because we are yet to initiate a proper 
conversation between the verbal and the visual, for the obvious reason that this is not so facile a task.

While photography, as paraphrased in a conversation with Derrida (2010), can be seen as the first optical medium to enter the domain of writing and to bring writing into the very essence of the image, the dialectical relationship between the two creates tensions that are not easily resolved. Till then, in acknowledgement of the generic incompleteness or rather an in-progress status that marks the way we write the city in text or in images, and contrary to Benjamin's (1972) belief that there is a point when the caption must step in without which photographic construction would remain stuck in the approximate, the photographs presented here are deliberately left uncaptioned. Elvin Wyly $(2010,511,525)$, in the very pages of this journal had once suggested: 'What if we choose a very small sample of images, and try to diagram some of the contemporary social forces...Whenever the subject comes into view, seize the opportunity. Zoom, focus, release the shutter. Then write the caption.' My reluctance to 'write the caption' is not in any sense to leave them unblemished but in acknowledgment of an equally important character here besides the writer and the photographer - that of the reader who is not just an incidental spectator but someone who through reading carries the onus of representation that images have come to be associated with. Thus, while I think of this essay itself as an extended caption offering important clues to the way these photographs could be read, I leave to the reader, the task of writing the caption, or a counter-caption.

\section{Acknowledgements:}

Reflections in this essay first took roots during my 2017-18 EURIAS Fellowship held at the Paris Institute for Advanced Studies (France), co-funded by Marie SkłodowskaCurie Actions, under the European Union's 7th Framework Programme for research, and a funding from the French State programme "Investissements d'avenir", managed by the Agence Nationale de la Recherche (ANR-11-LABX-0027-01 Labex RFIEA+). Collaboration with the photographer was supported by a UCL Global Engagement Fund project 'Picturing Chennai: Photography as an urban narrative' (2018-19). I am grateful to Dr Aurelie Varrel at EHESS, Paris for having partnered us on this initiative. Photographs were exhibited at Alliance Française of Madras where the enthusiastic participation of the wider public helped me think through some of the intellectually fussy questions in a more mundane manner. I would also like to thank Dr Debbie Humphrey 
for suggesting that I write this essay in the first instance as well as acknowledge the patience of my editorial colleagues who have waited till the very last minute for me to pull this off. Matthew Gandy, reliable as always, provided very valuable comments. All photographs @ Christophe Delory.

References:

Benjamin, W. (1972). "A short history of photography." Screen 13(1): 5-26.

Boeck, F. d. (2016). Suturing the city: Living together in Congo's urban worlds. London, Autograph ABP.

Boeck, F. d. and A. Simone (2015). "Kinshasa's fluxes and rhythms." Cityscapes 7: 8595.

Burris, J. (2011). "The urban photogenie of architainment." The Journal of Aesthetics and Art Criticism 69(1): 93-103.

Chesher, C. (2012). Between image and information: The iPhone camera in the history of photography. Studying mobile media: Cultural technologies, mobile communications and the iPhone. L. Hjorth, J. Burgess and I. Richardson. New York, Routledge: 98-117.

Cronon, W. (1992). "A place for stories: Nature, history, and narrative." The Journal of American History 78(4): 1347-1376.

Derrida, J. (2010). Copy, archive, signature: A conversation on photography. Stanford, CA, Stanford University y Press.

Filip de Boeck \& and M.-F. Plissart (2014 [2003]). Kinshasa: Tales of the invisible city. Antwerp, Ludion Press.

Mitchell, W. J. T. (1994). Picture theory: Essays on verbal and visual representation. Chicago and London, The University of Chicago Press.

Rao, z. W. (2009). "Embracing urbanism: The city as archive." New Literary History 40(2): 371-383.

Robinson, J. (2013). "The urban now: Theorising cities beyond the new." European Journal of Cultural Studies 16(6): 659-677.

Roy, A. (2003). City Requiem, Calcutta: Gender and the Politics of Poverty. Minneapolis, University of Minnesota Press.

Wyly, E. (2010). "Things pictures don't tell us: In search of Baltimore." Cityscapes 14(5): 497-528. 
Pushpa Arabindoo is an Associate Professor in Geography \& Urban Design at University College London where she is also a co-director of the UCL Urban Laboratory. Email: p.arabindoo@ucl.ac.uk

Christophe Delory is a French photographer based in France. His main work is in portrait photography. After studying mathematics, he graduated from the French Society of Photography and has since worked on several commissions around the world. For ten years, he photographed intellectuals while pursuing a personal work on craftsmen, as well as a photographic historiography of a Second World War bunker. Email: photochristophedelory@gmail.com 


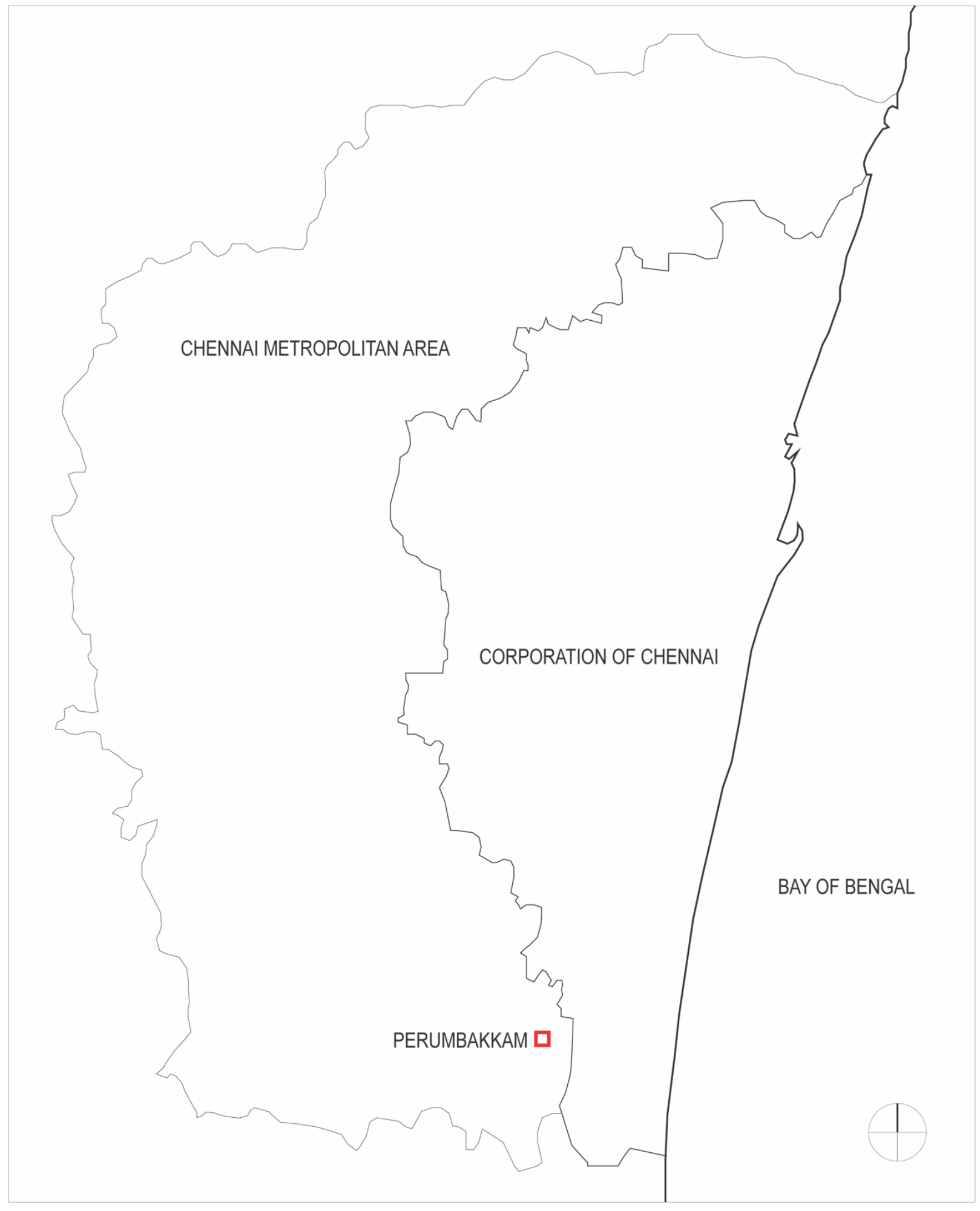

Map of Chennai City and Metropolitan Area 


\section{Spectral City: Excavating Chennai from Madras}




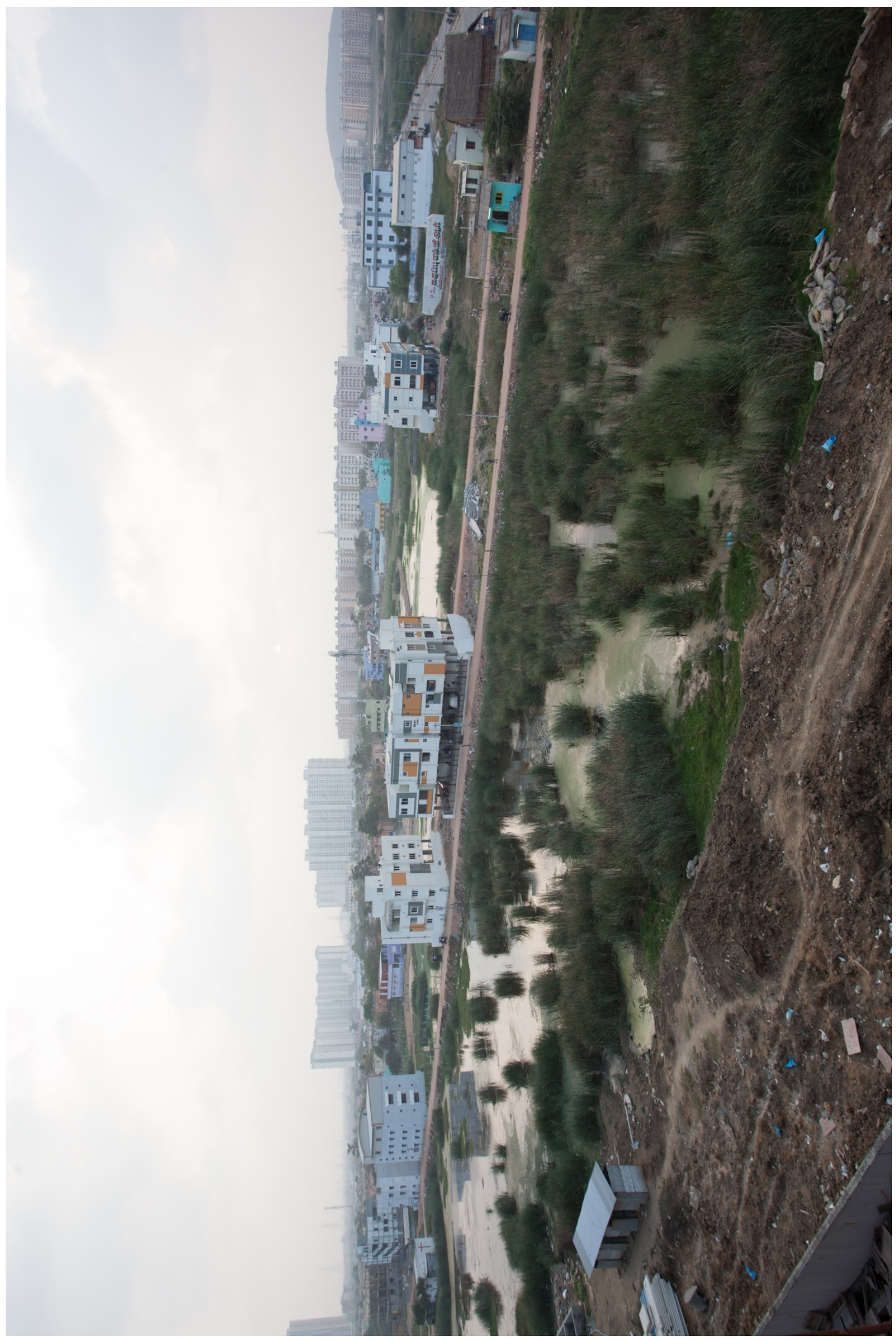




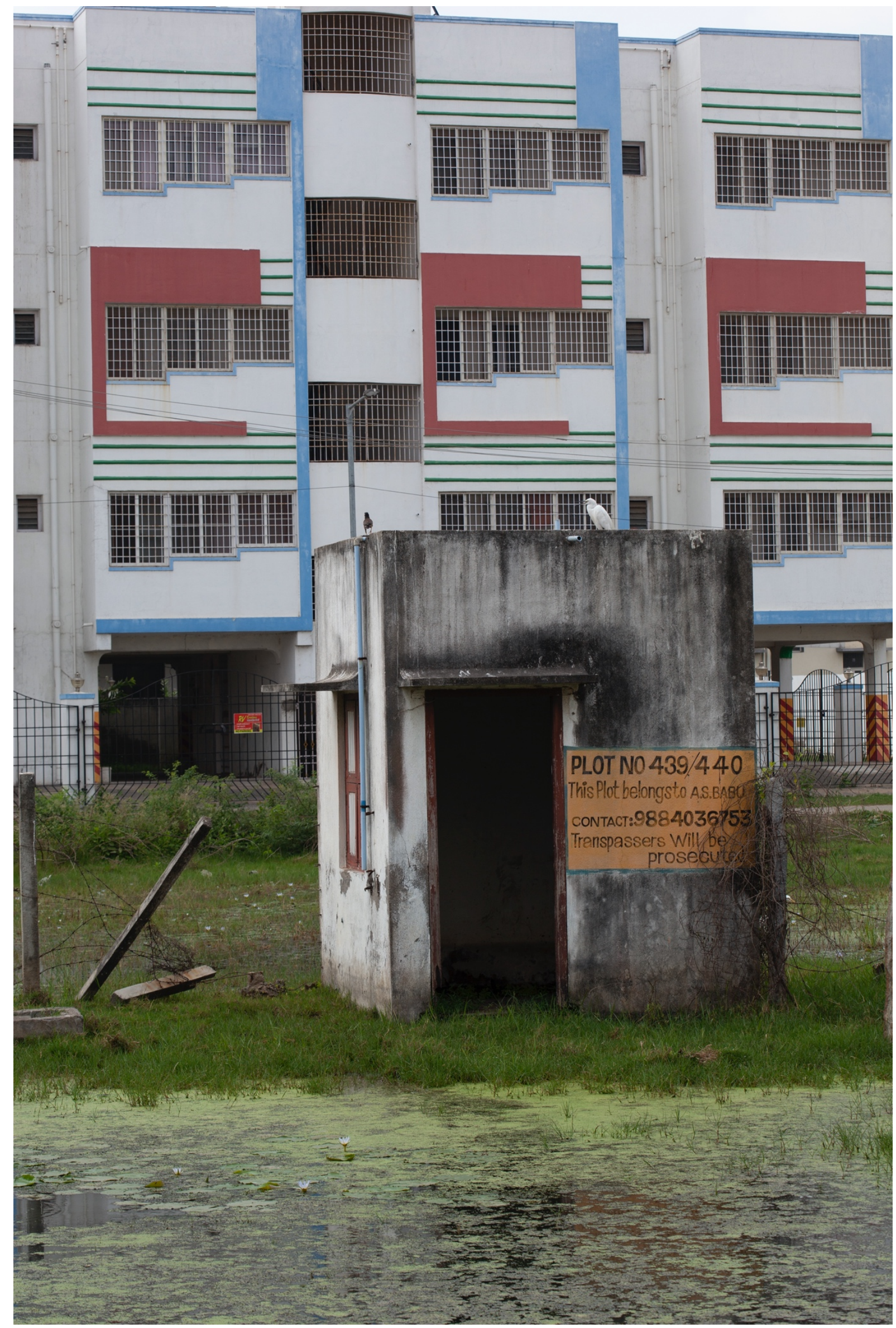



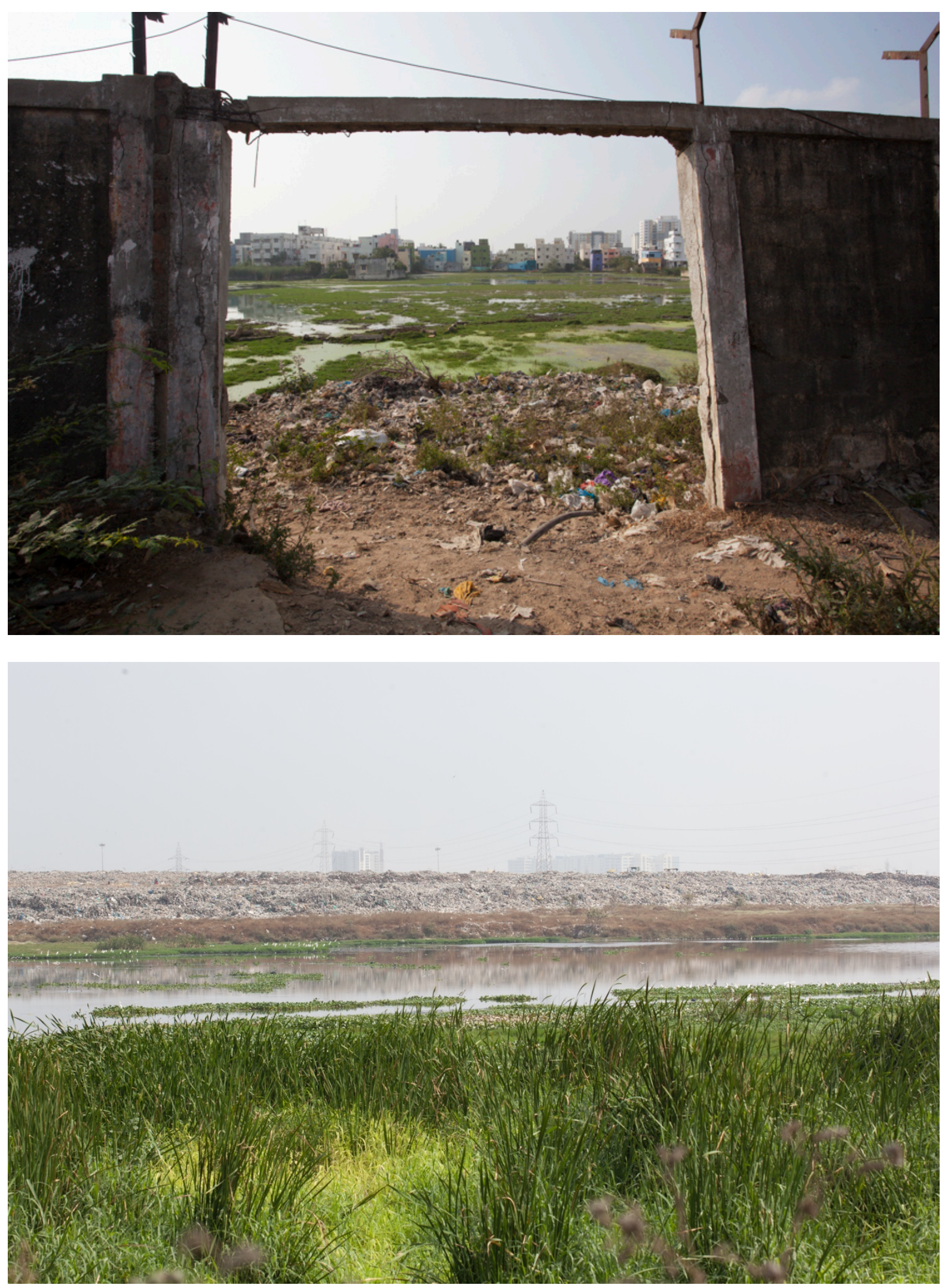


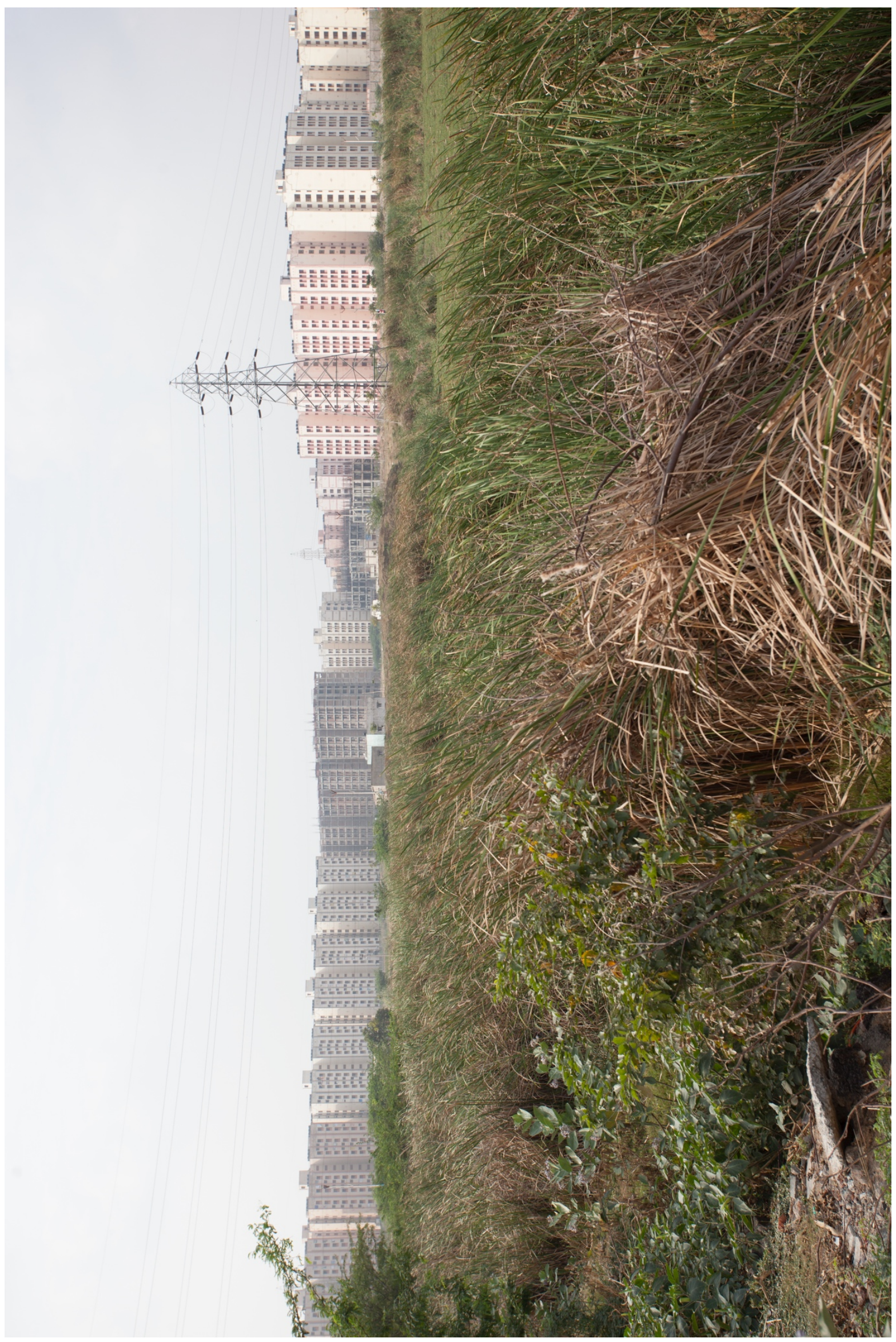



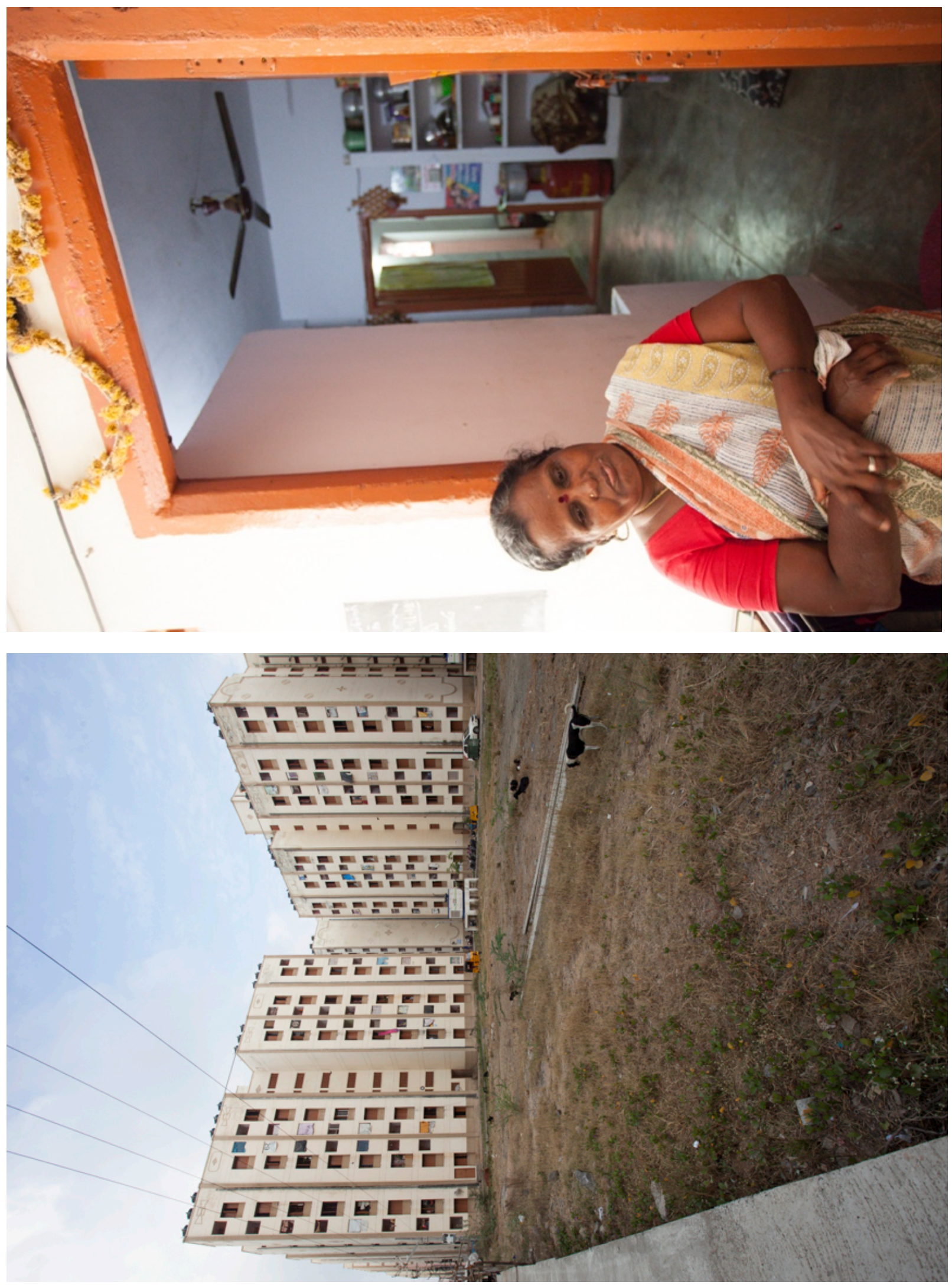


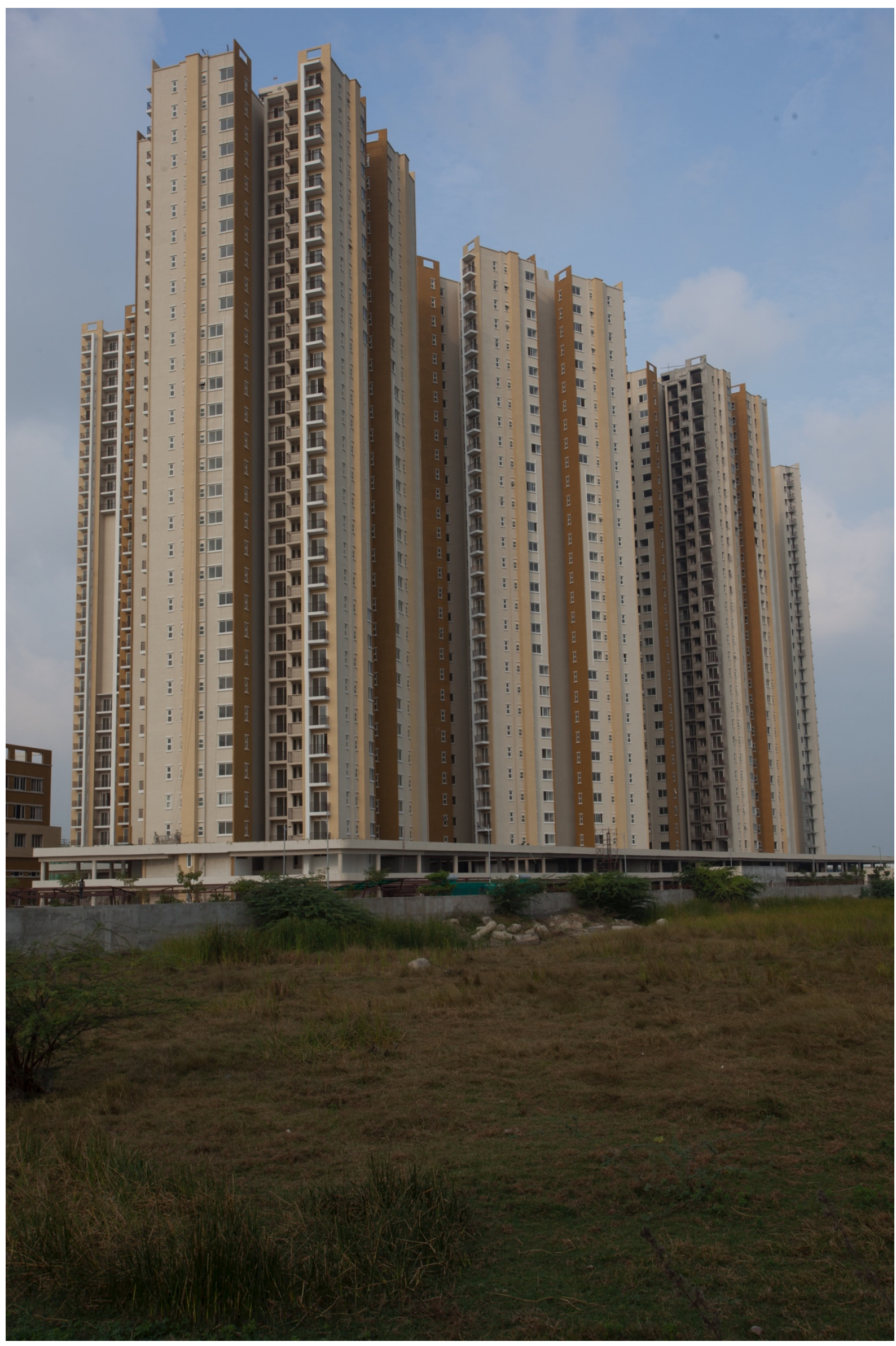




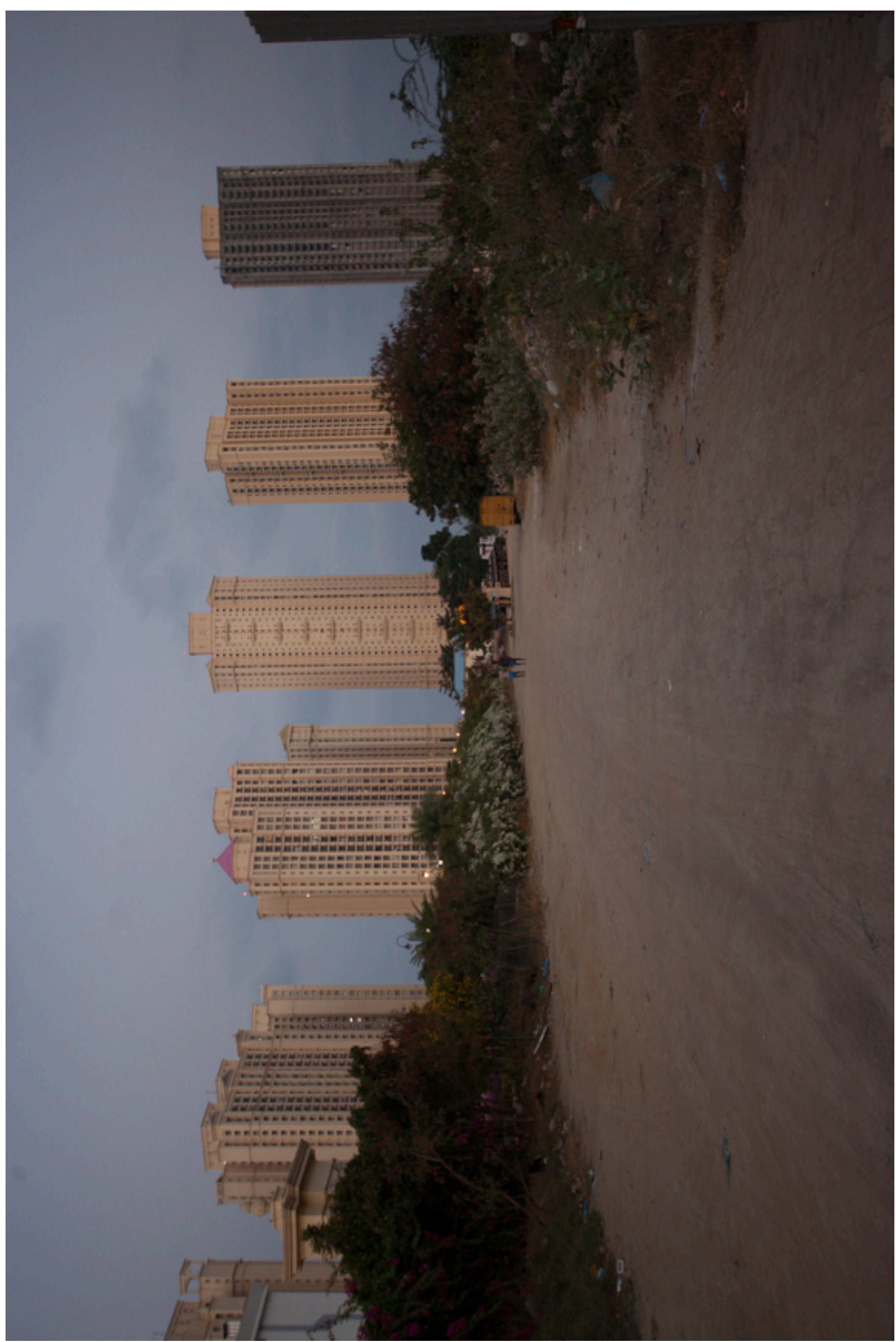

